\title{
Basic transcription factor 3 expression silencing attenuates colon cancer cell proliferation and migration in vitro
}

\author{
XU LI, JINKE SUI, JUNJIE XING, FUAO CAO, HAO WANG, CHUANGANG FU and HANTAO WANG
}

Department of Colorectal Surgery, Changhai Hospital, Shanghai 200433, P.R. China

Received November 28, 2015; Accepted July 27, 2018

DOI: $10.3892 / \mathrm{ol} .2018 .9613$

\begin{abstract}
Basic transcription factor 3 (BTF3) is an RNA polymerase II transcription factor that also regulates apoptosis. Numerous studies have identified that BTF3 is aberrantly expressed in several types of tumor. However, the function of BTF3 in colorectal cancer remains unknown. The aim of the present study was to assess the function of BTF3 during colon cancer tumorigenesis. Applying a lentivirus-transfected short hairpin RNA approach, expression of BTF3 was dysregulated in the colon cancer HCT116 and HT-29 cell lines; knockdown efficiency was verified using the quantitative polymerase chain reaction and western blotting. To determine the function of BTF3 in colon cancer, cell proliferation was assessed using an MTT assay, cell apoptosis and the cell cycle were assessed using flow cytometry, and cell migration was assessed using a Transwell assay. Knockdown of BTF3 inhibited cell proliferation, possibly because BTF3 knockdown induced cell early apoptosis and arrested cells in $\mathrm{G}_{0}-\mathrm{G}_{1}$ phase. BTF3 knockdown also inhibited cell migration. The results of the present study identified that BTF3 expression is associated with colon cancer progress, and BTF3 may therefore be a molecular marker for diagnosis and treatment outcomes of human colon cancer.
\end{abstract}

\section{Introduction}

Different transcription factors serve various functions in multiple physiological mechanisms, including cell cycle progression, cell metabolism, growth and development (1). Basic transcription factor 3 (BTF3) is involved in various biotic and abiotic stress processes, as well as different physiological and developmental mechanisms $(2,3)$.

BTF3 is encoded by the human BTF3 gene and is evolutionarily conserved in a range of organisms $(4,5)$. BTF3 was initially described as a member of the general transcription

Correspondence to: Dr Hantao Wang, Department of Colorectal Surgery, Changhai Hospital, 168 Changhai Road, Shanghai 200433, P.R. China

E-mail: hantaowang1234@163.com

Key words: colon cancer, basic transcription factor 3, proliferation, apoptosis, migration, cell cycle machinery and forms a stable complex with the RNA polymerases (6). BTF3 initiates transcription by binding to promoter elements such as the TATA and CAAT box sequences in the promoter region $(7,8)$. Owing to alternative splicing, BTF3 is present in two different isoforms: BTF3a and BTF3b. BTF3a is the transcriptionally active form of BTF3, whereas the BTF3b isoform, which lacks the $44 \mathrm{~N}$-terminal amino acids of BTF3a, is transcriptionally inactive, although it is able to bind to RNA polymerase II (9).

A previous mouse embryonic development study revealed that mice homozygous for a loss-of-function mutation in the BTF3 gene succumbed early in development, indicating its function in biological development (10). In addition to its functions as transcription regulator, BTF3 also aids the regulation of the cell cycle and apoptosis $(11,12)$. Decreased BTF3 expression is associated with increased apoptosis in lymphocytes (13), and downregulation of BTF3 inhibits transcription and protein synthesis (14). In Caenorhabditis elegans, overexpression of BTF3 prevents cell apoptosis, whereas the RNA interference-mediated knockdown of BTF3 induces cell apoptosis (11). In human cancer, BTF3 is overexpressed in glioma (15), hepatocarcinoma (16) and pancreatic ductal adenocarcinoma (17). Downregulation of BTF3 decreases the expression of several cancer-associated genes, including ephrin receptor B2 (18), heparanase 2 (19) and the oncogene ABL proto-oncogene 2 , non-receptor tyrosine kinase (20). In breast cancer, BTF3 interacts with either $17 \beta$-estradiol or estrogen receptor $\alpha(\mathrm{ER} \alpha)$ through its AF1 domain and upregulates the transcriptional response of ER $\alpha$ reporter genes $(21,22)$. These results suggest that BTF3 also serves an important function in tumor occurrence and the development of tumor progression.

The molecular mechanism of BTF3 in colon cancer remains unclear. In order to investigate the function of BTF3 in colon cancer, the present study used a lentivirus-mediated short hairpin RNA (shRNA) approach to target BTF3 to knockdown its expression in human colon cancer cells. In addition, the effect of BTF3-knockdown on cell proliferation, the cell cycle, cell apoptosis and migration was investigated. The results of the present study provide information on a novel molecular target for the diagnosis and therapy of colon cancer.

\section{Materials and methods}

Cell culture. The colon cancer HCT116 and HT-29 cell lines, and 293 cells were purchased from the American Type Culture 
Collection (Manassas, VA, USA). All cells were grown in complete Dulbecco's medium Eagle's medium (DMEM; HyClone; GE Healthcare Life Sciences, Logan, UT, USA), supplemented with $10 \%$ fetal bovine serum (HyClone; GE Healthcare Life Sciences), and $100 \mathrm{U} / \mathrm{ml}$ penicillin and streptomycin (Gibco; Thermo Fisher Scientific, Waltham, MA, USA), and incubated at $37^{\circ} \mathrm{C}$ in a $5 \% \mathrm{CO}_{2}$ atmosphere.

Plasmid and vector construction. The selected and optimized shRNA against human BTF3 (5'-GCAGCGAAC ACTTTCACCATT-3') was transfected into the lentiviral vector pLKO.1-pure (Addgene, Inc., Cambridge, MA, USA). The constructed shBTF3 plasmid and control vector were further co-transfected with Lipofectamine 2000 (Thermo Fisher Scientific, Inc.) into 293 cells with packaging plasmids (preserved in our lab) to generate a shBTF3-expressing lentivirus or empty vector lentivirus. Cells $\left(1 \times 10^{6}\right)$ were cultured in a $10-\mathrm{cm}$ dish and incubated at $37^{\circ} \mathrm{C}$ for $24 \mathrm{~h}$. Control lentivirus and BTF3-targeted shRNA lentivirus were then used to transfect the HCT116 and HT-29 cells. Following selection in $2 \mu \mathrm{g} / \mathrm{ml}$ puromycin (Thermo Fisher, Scientific, Inc.) for 1 week, cells were collected to evaluate the knockdown efficiency.

Reverse transcription-quantitative polymerase chain reaction (RT-qPCR). Total RNA was extracted from BTF3-knockdown cell lines (those transfected with BTF3-targeted shRNA), the empty vector control cell line (Vector) and non-transfected cells using an RNeasy mini kit (Qiagen China Co., Ltd., Shanghai, China), according to the manufacturer's protocol. cDNA was generated by reverse transcription of $1-\mu \mathrm{g}$ aliquots of RNA using the Takara PrimeScript RT Reagent kit (Takara Biotechnology Co., Ltd., Dalian, China) according to the manufacturer's protocol. The cDNA was used for qPCR using the SYBR Premix Ex-Taq kit (Takara Biotechnology Co., Ltd.) on a CFX96 instrument qPCR system (Bio-Rad Laboratories, Inc., Hercules, CA, USA). The PCR was performed according to the manufacturer's instructions: Initial denaturation was at $95^{\circ} \mathrm{C}$ for $10 \mathrm{~min}$ followed by 30 cycles at $95^{\circ} \mathrm{C}$ for $1 \mathrm{~min}$, annealing at $53^{\circ} \mathrm{C}$ for $1 \mathrm{~min}$, extension at $72^{\circ} \mathrm{C}$ for $1 \mathrm{~min}$, and final extension at $72^{\circ} \mathrm{C}$ for $5 \mathrm{~min}$. All expression data were normalized to $\beta$-actin levels using $2^{-\Delta \Delta \mathrm{Cq}}$ method (23). Primer sequences were as follows: $\beta$-actin, 5'-CGAGCGCGGCTA CAGCT-3' (forward) and 5'-TCCTTAATGTCACGCACG ATTT-3' (reverse); and BTF3 5'-AGCTTGGTGCGGATA GTCTGA-3' (forward) and 5'-GTGCTTTTCCATCCACAG ATTG-3' (reverse).

Western blotting. Cells were lysed in radioimmunoprecipitation buffer (Cell Signaling Technology, Inc., Danvers, MA, USA), containing Complete protease inhibitors (Roche Applied Science, Penzberg, Germany), phosphatase inhibitors (Roche Applied Science), 5 mM dithiothreitol (Sigma-Aldrich; Merck KGaA, Darmstadt, Germany) and $1 \mathrm{mM}$ phenylmethylsulfonyl fluoride (Sigma-Aldrich; Merck KGaA) for 15 min, and then centrifuged at $15,000 \mathrm{x}$ g for $10 \mathrm{~min}$ at $4^{\circ} \mathrm{C}$. The supernatant was collected and protein concentration was quantified using the Bio-Rad Protein assay kit II \#5000002 (Bio-Rad Laboratories, Inc.). The proteins were separated by SDS-PAGE (10\% gel), blotted onto a polyvinylidene fluoride membrane (Merck KGaA), and then blocked for $1 \mathrm{~h}$ at room temperature in TBST with $2 \%$ non-fat milk, followed by overnight incubation at $4{ }^{\circ} \mathrm{C}$ with anti-BTF3 (Abnova, Taipei, Taiwan; Catalog no. H00000689-R01) or anti- $\beta$-actin (Cell Signaling Technology, Inc.; Catalog no. 3700) antibodies $(1: 1,000)$. Membranes were rinsed with Tris-buffered saline containing Tween-20 (TBST) with $0.05 \%$ Tween-20 and incubated for $2 \mathrm{~h}$ with a 1:5,000 diluted HRP-conjugated goat anti-human IgG secondary antibody (Thermo Fisher Scientific, Inc.; Catalog no. A18847). Following another three washes with TBST, target proteins were detected using an Enhanced Chemiluminescence detection kit (Pierce; Thermo Fisher Scientific, Inc.). Quantification of the western blot analysis was performed using ImageJ software v1.8.0 (National Institutes of Health, Bethesda, MD, USA).

MTT assay. The shBTF3 shBTF3-expressing lentivirus or empty vector lentivirus was transfected into HCT116 and HT-29 cells the knockdown efficiency were examined. HCT116 and HT-29 cells were seeded at $3 \times 10^{3}$ cells per well at $37^{\circ} \mathrm{C}$ in 96-well plates and cell viability was assessed every day for 4 days. In brief, at the start of each assay, $20 \mu 1$ MTT (with $5 \mathrm{mg} / \mathrm{ml}$ thiazolyl blue tetrazolium bromide; Sigma-Aldrich; Merck $\mathrm{KGaA}$ ) was added to each well and then the plate was incubated for an additional $4 \mathrm{~h}$. Culture medium was removed from the wells, $100 \mu 1$ dimethylsulfoxide (Sigma-Aldrich; Merck $\mathrm{KGaA}$ ) was added to each well and plates were incubated for $20 \mathrm{~min}$ at $37^{\circ} \mathrm{C}$. Absorbance was determined using a microplate reader (Bio-Rad Laboratories, Inc.) at a wavelength of $495 \mathrm{~nm}$. Each experiment was performed three times.

Transwell assay. The cell migration assay was carried out using a modified Boyden chamber plate with $8-\mu \mathrm{m}$ pore size polycarbonate membrane filters (Corning Incorporated, Corning, NY, USA) (24). ShBTF3- and empty vector-transfected HTC116 and HT-29 cells, along with non-transfected HTC116 and HT-29 cells, were incubated at $37^{\circ} \mathrm{C}$ in DMEM for $6 \mathrm{~h}$. Subsequently, $1 \times 10^{4}$ cells from each group and cell type were added to the upper part of the Boyden chamber, and the bottom chamber was filled with DMEM containing 20\% serum. The cells were allowed to migrate to the underside of the membrane during incubation for $48 \mathrm{~h}$ at $37^{\circ} \mathrm{C}$. Next, the cells on the membrane filter were fixed with $4 \%$ paraformaldehyde and stained with $0.05 \%$ Giemsa (Sigma-Aldrich; Merck KGaA). The migration index was defined as the number of cells that had migrated to the membrane filter by cell counting in at least three random fields using a light microscope (magnification, x200) per filter.

Flow cytometric assays. Cells were harvested using trypsin/EDTA (Gibco; Thermo Fisher Scientific, Inc.) from 6-cm-diameter dishes. Following centrifugation 1,200 x g for $15 \mathrm{~min}$ at $4^{\circ} \mathrm{C}$, pellets were then washed with PBS and centrifuged again. Following resuspension in binding buffer (10 mmol/1 HEPES, $140 \mathrm{mmol} / 1 \mathrm{NaCl}, 5 \mathrm{mmol} / 1 \mathrm{CaCl}_{2}$ ), cells were incubated with annexin $\mathrm{V}$ and propidium iodide (PI) according to the manufacturer's protocol (BioVision, Inc., Milpitas, CA, USA). Cells were analyzed using a FACSCanto II flow cytometer (BD Biosciences, Franklin Lakes, NJ, USA) and FlowJo software v10.0 (Tree Star, Inc., Ashland, OR, USA). For cell cycle analysis, cells were washed twice with 
A
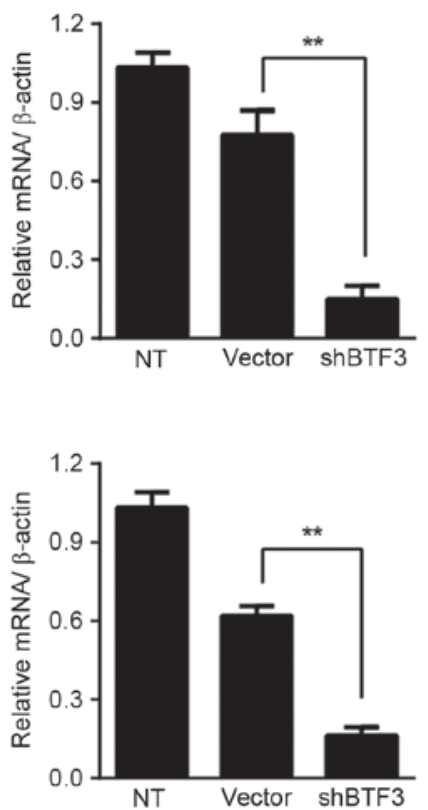

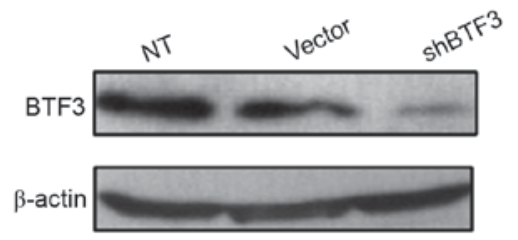

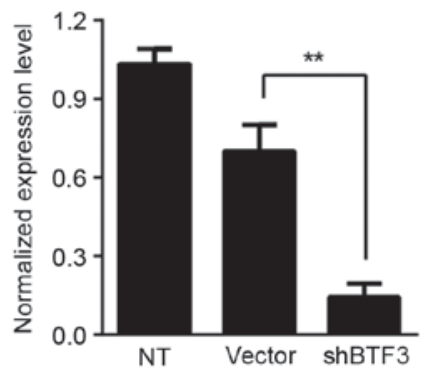

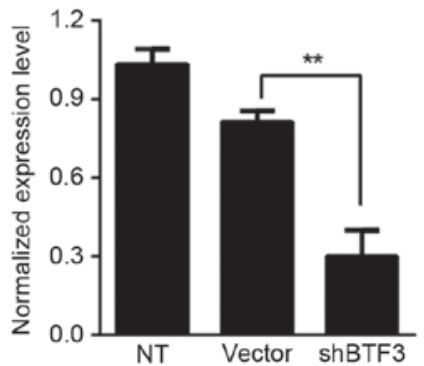

Figure 1. shRNA BTF3 knockdown in colon cancer HCT116 and HT-29 cells. (A) Quantitative polymerase chain reaction analysis detected BTF3 mRNA levels in empty vector control, shRNA-BTF3 lentivirus-transfected, and non-transfected HCT116 (top) and HT-29 (bottom) cells. (B) Western blot analysis of BTF3 protein expression in empty vector control and shRNA-BTF3 lentivirus-transfected, and in non-transfected HCT116 (top) and HT-29 (bottom) cells. $\beta$-actin was used as loading control. (C) Semi-quantitative densitometry analysis of BTF3 protein levels in HCT116 (top) and HT-29 (bottom) cells. "* P<0.01. NT, non-transfected; shRNA, short hairpin RNA; BTF3, basic transcription factor 3; shBTF3, short hairpin BTF3.

ice-cold PBS and fixed using $70 \%$ ethanol overnight at $4^{\circ} \mathrm{C}$. The cells were then digested with $50 \mu \mathrm{g} / \mathrm{ml}$ RNase A in $100 \mu \mathrm{l}$ PBS and stained with $20 \mu \mathrm{g} / \mathrm{ml}$ PI for $30 \mathrm{~min}$ at $37^{\circ} \mathrm{C}$. Cells were then analyzed using a FACSCanto II flow cytometer (BD Biosciences) and FlowJo software.

Statistical analysis. Data are presented as the mean \pm standard deviation. Statistical comparisons were made using one-way analysis of variance with a least significant difference post hoc test or an unpaired Student's t-test. $\mathrm{P}<0.05$ was considered to indicate a statistically significant difference. Each experiment was performed at least three times.

\section{Results}

Lentivirus-mediated knockdown of BTF3 in human colon cancer cells. In order to investigate the function of BTF3 in colon cancer, a lentivirus vector was used to generate BTF3-knockdown stable HCT116 and HT-29 cell lines. Following selection in puromycin for 1 week and once stable cell proliferation was achieved, qPCR and western blot analysis were performed to assess the efficiency of BTF3-knockdown. As presented in Fig. 1A, expression of BTF3 mRNA in HCT116 cells transfected with shBTF3 lentivirus was $80 \%$ lower compared with that in non-transfected cells and $60 \%$ lower compared with that in cells transfected with the empty vector control $(\mathrm{P}<0.01)$. Similar results were obtained in the HT-29 cell line (Fig. 1A). Comparing BTF3-knockdown and empty vector-treated cells, the BTF3 protein level appeared to be markedly decreased in HCT116 and HT-29 cells (Fig. 1B). The semi-quantitative results of western blot densitometry analysis revealed that there was a significant difference in the
BTF3 protein expression level between shBTF3 and empty vector-treated cells $(\mathrm{P}<0.01 ;$ Fig. 1C).

Knockdown of BTF3 inhibits proliferation of colon cancer cells. To assess the effect of BTF3 on colon cancer cell proliferation, BTF3-knockdown, empty vector control- and non-transfected HCT116 and HT-29 cells were seeded in 96-well-plates and a series of MTT assays were performed. The results of these assays revealed that cell proliferation in BTF3-knockdown HCT116 and HT-29 cells was significantly decreased over the course of the 4 days, compared with controls $(\mathrm{P}<0.01$; Fig. $2 \mathrm{~A}$ and $\mathrm{B})$. These results suggest that BTF3 knockdown significantly decreased the proliferation of colon cancer cells.

BTF3 knockdown induces early apoptosis and arrests cells in $G_{0^{-}} G_{1}$ phase. To explore further the mechanism by which BTF3 knockdown inhibits cell proliferation, cell apoptosis was examined through annexin V/PI double staining for apoptotic cells. There was a significant increase in early apoptosis (annexin V-positive, PI-negative) in BTF3-knockdown compared with NT (non-transfected) control cells, from $4.42 \pm 1.33$ to $25.13 \pm 1.65 \%$ ( $\mathrm{P}<0.01$; Fig. 3 ). This result indicated that BTF3 may be involved in colon cancer cell survival. In order to determine the function of BTF3 in cell-cycle progression, flow cytometry was used to assess the changes in cell cycle distribution prior to and following BTF3-knockdown in HTC116 cells. In vector control cells, the cell distribution was: $\mathrm{G}_{0}-\mathrm{G}_{1}$ phase, $45.52 \pm 1.09 \%$; $\mathrm{S}$ phase, $3.08 \pm 0.27 \% ; \mathrm{G}_{2}-\mathrm{M}$ phase, $51.58 \pm 1.06 \%$. Following BTF3 knockdown, cell distribution altered to: $\mathrm{G}_{0}-\mathrm{G}_{1}$ phase, $62.41 \pm 1.33 \%$; $\mathrm{S}$ phase, $1.95 \pm 0.32 \%$; $\mathrm{G}_{2}-\mathrm{M}$ phase, $36.01 \pm 1.21 \%$ (Fig. 3B). Comparing the control and 
A

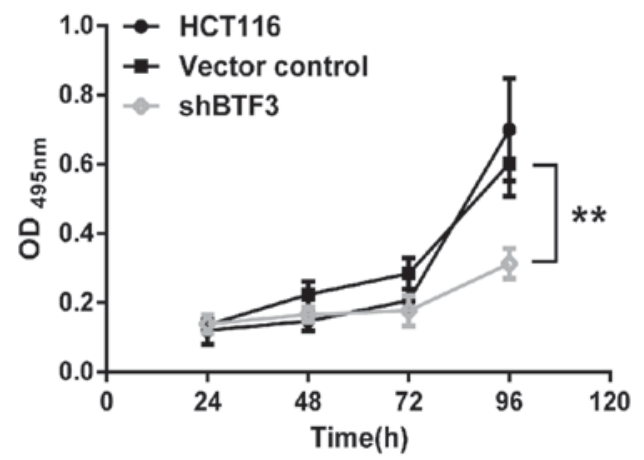

B

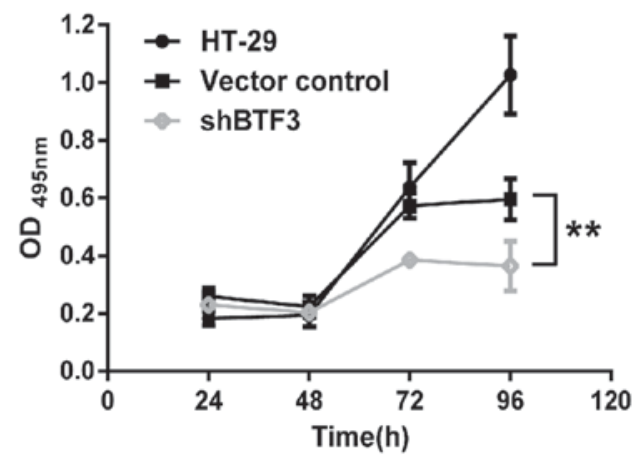

Figure 2. Knockdown of BTF3 inhibits cell proliferation in colon cancer cells. The proliferation of (A) HCT116 and (B) HT-29 cells following lentiviral transfection with empty vector control or shBTF3 was assessed using an MTT assay. ${ }^{* *} \mathrm{P}<0.01$. shRNA, short hairpin RNA; BTF3, basic transcription factor 3; OD, optical density.

A
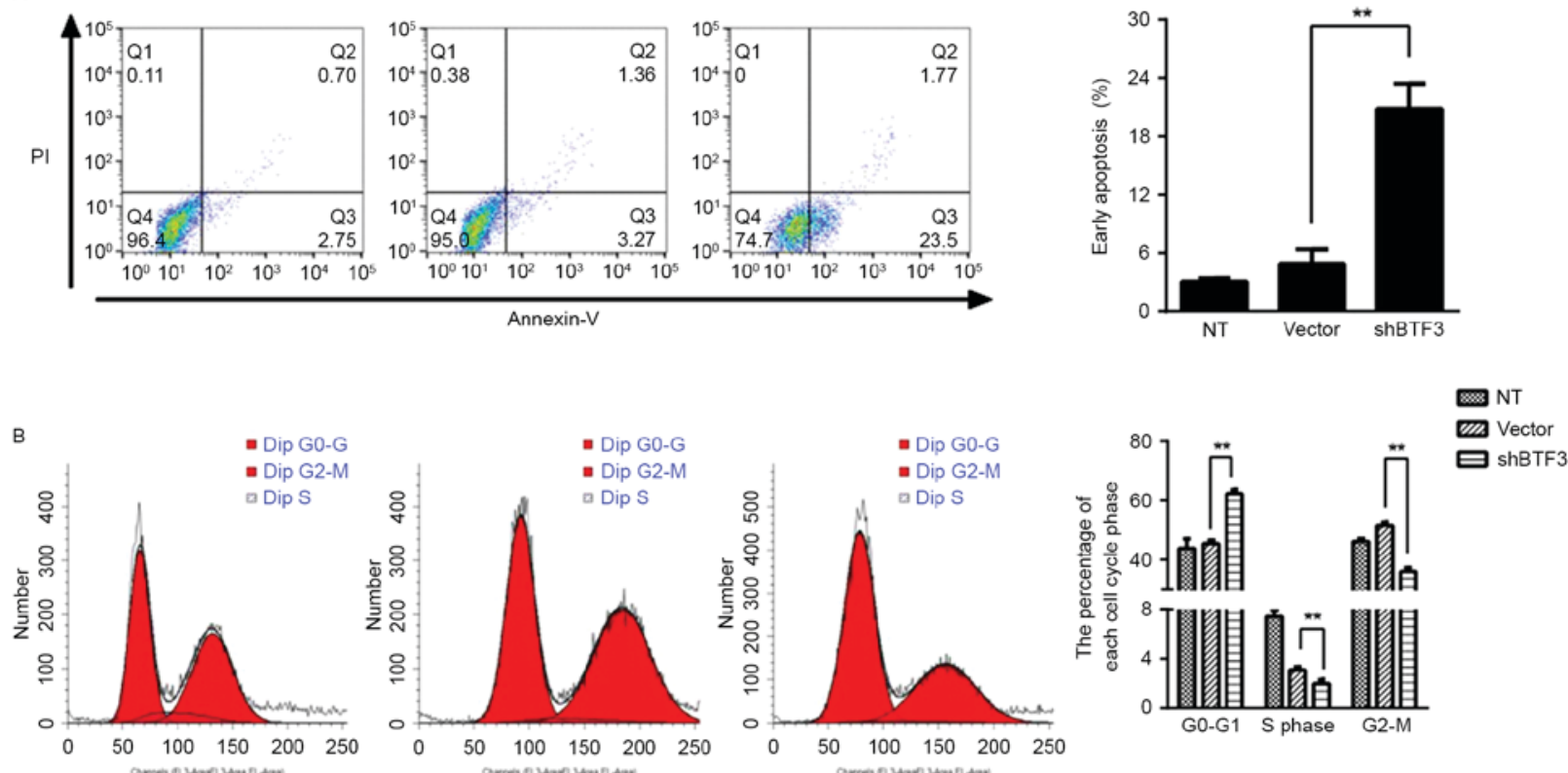

Figure 3. BTF3 knockdown induces HCT116 cells early apoptosis and arrested cells in $\mathrm{G}_{0}-\mathrm{G}_{1}$ phase of the cell cycle. (A) Flow cytometric analysis of empty vector control, shBTF3-transfected cells and non-transfected HCT116 cells apoptosis using annexin V and PI double staining. The proportion of early apoptotic cells (annexin-V-positive and PI-negative) was quantified. (B) Cell cycle distribution of empty vector control, shBTF3-transfected or non-transfected HCT116 cells determined by flow cytometry. ${ }^{* *} \mathrm{P}<0.01$. BTF3, basic transcription factor 3; shRNA, short hairpin RNA; NT, non-transfected; PI, propidium iodide; shBTF3, short hairpin BTF3; Dip, diploid peak.

BTF3-knockdown cells revealed that cell distribution in the $\mathrm{G}_{0}-\mathrm{G}_{1}$ phase was significantly increased by BTF3-knockdown $(\mathrm{P}<0.01)$, and the proportion of cells in $\mathrm{S}$ and $\mathrm{G}_{2}-\mathrm{M}$ phase was significantly decreased $(\mathrm{P}<0.01)$. These results indicated that BTF3 knockdown may be involved in cell-cycle regulation as the BTF3-knockdown cells were arrested at $G_{0}-G_{1}$ phase, decreasing the proportion of cells undergoing mitosis and therefore inhibiting cell proliferation.

Knockdown of BTF3 inhibits colon cancer cell migration. Cell proliferation and migration are two characteristics of tumor cells. The aforementioned results indicated that BTF3 knockdown is able to inhibit the proliferation of colon cancer cells. Whether BTF3 knockdown alters cell migration was assessed using a Transwell assay. A change in cell migratory ability was observed following BTF3 knockdown in HTC116 and HT-29 cells (Fig. 4A). Compared with empty vector-transfected control cells, the migration index of BTF3-knockdown cells decreased significantly by 79.7 and $66.3 \%$, in HTC116 and HT-29, respectively $(\mathrm{P}<0.01$; Fig. 4B). These results indicated that BTF3 knockdown may significantly inhibit the migration of colon cancer cells.

\section{Discussion}

BTF3, which functions as an additional transcription factor II-associated protein, does not bind to proximal promoter regions directly, but forms a stable complex with RNA polymerase II and is a part of the gene transcription initiation complex $(4,7)$. Several studies have indicated that the expression 
A
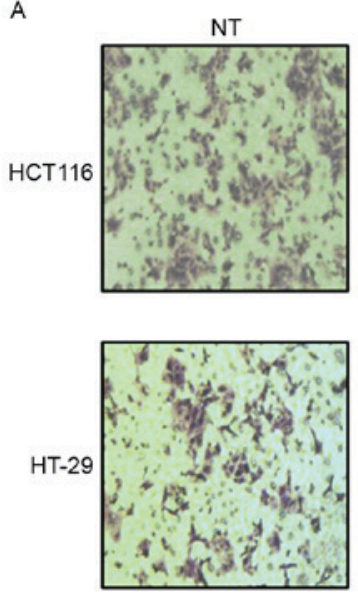

Vector
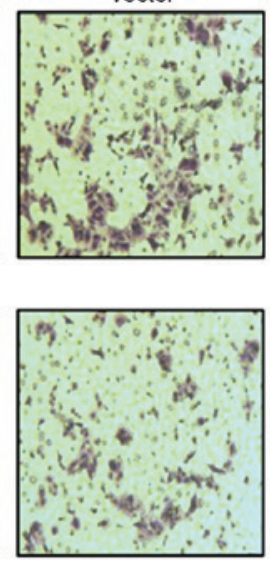

shBTF3
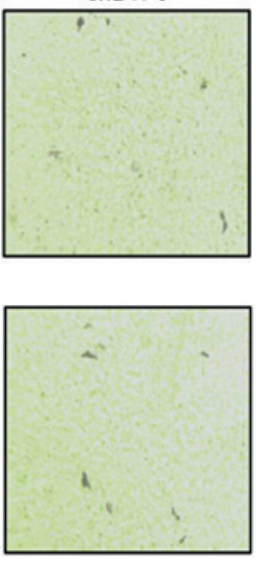

B
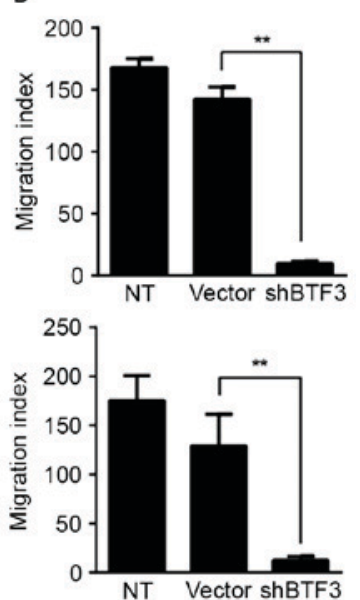

Figure 4. BTF3 knockdown inhibits human colon cancer cell motility. (A) The migratory ability of human colon cancer HCT116 (top) and HT-29 (bottom) cell lines transfected with an empty vector control or with shBTF3 was assessed using a Transwell assay, as was that of non-transfected cells. (B) Quantification of migration indices. Each experiment was performed in triplicate. ${ }^{* *} \mathrm{P}<0.01$. BTF3, basic transcription factor 3; shRNA, short hairpin RNA; NT, non-transfected; shBTF3, short hairpin BTF3.

pattern of BTF3 is frequently disordered in tumors $(13,17)$. On the other hand, BTF3 is also highly expressed in malignant tissue and affects the invasion and proliferation of tumor cells, which indicates that BTF3 may serve as an independent diagnostic factor (25). By analyzing clinical data from colorectal cancer patients, Wang et al (26) identified that BTF3 overexpression may be an early event in colon cancer and may be a useful biomarker for early-stage colon cancer. In addition, BTF3 expression is associated with the expression of nuclear factor $\kappa \mathrm{B}, \mathrm{RAD} 50$ double-strand break repair protein, MRE11 homolog, double-strand break repair nuclease, nibrin and metadherin (26). This change in BTF3 expression may affect these signaling pathways, although the molecular mechanism of BTF3 in colon cancer remains unknown.

A shRNA targeting BTF3 was lentivirally transfected into HCT116 and HT-29 human colon cancer cells. The results demonstrated that knockdown of BTF3 significantly inhibited the proliferation of colon cancer cells, and the amount of early apoptotic cells was significantly increased. The cell-cycle distribution of BTF3-knockdown cells was also altered. The percentage of cells in $G_{0}-G_{1}$ phase was significantly increased in BTF3-knockdown colon cancer cells, whereas those in $\mathrm{S}$ and $\mathrm{G}_{2}-\mathrm{M}$ phases was significantly decreased, which indicated that BTF3-knockdown cells underwent cell-cycle arrest in interphase $G_{0}-G_{1}$. As a result of this arrest, cells could not enter mitosis and early apoptosis was induced, thus leading to a decrease in the proliferation of colon cancer cells. Previous studies revealed that regulation of apoptosis is associated with cell-cycle regulation $(27,28)$. Although apoptosis may be induced at any point in the cell cycle, the propensity for apoptosis to be induced differs markedly depending location of the cell within the cell cycle (29). Progression through the cell cycle is also subject to a number of regulatory proteins. For example, the progression through $G_{1}$ phase depends on the balance of cyclin D1 and cyclin-dependent kinase inhibitor 2A expression, owing to their identity as positive and negative regulators of progression through $\mathrm{G}_{1}$ phase, respectively (30). Therefore, whether BTF3 caused cells to arrest at $G_{0}-G_{1}$ phase owing to its regulation of cyclins warrants further research.

BTF3 also has an important function in other types of cancer. Liu et al (31) identified that BTF3 is potentially associated with the development and progression of gastric cancer. BTF3 is expressed at different levels in different stages of gastric cancer; low expression or gene silencing of BTF3 inhibited tumor growth and may be beneficial for gastric cancer treatment (31). In pancreatic ductal carcinoma, overexpression of BTF3 may be involved in cell-cycle progression, cell proliferation and extracellular matrix degradation (17). Using an immunohistochemical tissue array for the diagnosis and stratification of prostate cancer, Symes et al (32) identified that BTF3 expression was significantly upregulated in malignant prostate cancer tissue compared with non-malignant tissue. Therefore, BTF3 has the potential to be used as a specific molecular marker for the diagnosis and stratification of prostate cancer (32). The results of the present study indicated that, in colon cancer cells, BTF3 knockdown inhibited cell proliferation and promoted early apoptosis, suggesting an association between BTF3 expression and colon cancer.

In conclusion, the results of the present study shed light on the biological function of BTF3 in colon cancer. The results of the present study demonstrated that BTF3 knockdown is able to inhibit the proliferation of colon cancer cells, suggesting that BTF3 may promote the occurrence of colon cancer. BTF3 may therefore serve as a biomarker for the diagnosis of colon cancer and provide a molecular target for tumor gene therapy.

\section{Acknowledgements}

Not applicable.

\section{Funding}

The present study was supported by the National Natural Science Foundation of China (grant no. 81702297). 


\section{Availability of data and materials}

The datasets used and/or analyzed during the present study are available from the corresponding author on reasonable request.

\section{Authors' contributions}

XL carried out the design of the study, drafted the manuscript. JS conducted the cellular function experiments. JX performed molecular genetics examination. FC carried out the statistical analysis. HW helped the design the study and draft the manuscript. CF and HTW conceived the study, and participated in its design and coordination. All authors read and approved the final manuscript.

\section{Ethics approval and consent to participate}

Not applicable.

\section{Patient consent for publication}

Not applicable.

\section{Competing interests}

The authors declare that they have no competing interests

\section{References}

1. Hussain SS, Kayani MA and Amjad M: Transcription factors as tools to engineer enhanced drought stress tolerance in plants. Biotechnol Prog 27: 297-306, 2011.

2. Wang W, Xu M, Wang Y and Jamil M: Basal transcription factor 3 plays an important role in seed germination and seedling growth of rice. Biomed Res Int 2014: 465739, 2014.

3. Wang Y, Zhang X, Lu S, Wang M, Wang L, Wang W, Cao F, Chen $\mathrm{H}$, Wang J, Zhang J and Tu J: Inhibition of a basal transcription factor 3-like gene Osj10gBTF3 in rice results in significant plant miniaturization and typical pollen abortion. Plant Cell Physiol 53: 2073-2089, 2012.

4. Zheng XM, Moncollin V, Egly JM and Chambon P: A general transcription factor forms a stable complex with RNA polymerase B (II). Cell 50: 361-368, 1987.

5. Cavallini B, Faus I, Matthes H, Chipoulet JM, Winsor B, Egly JM and Chambon P: Cloning of the gene encoding the yeast protein BTF1Y, which can substitute for the human TATA box-binding factor. Proc Natl Acad Sci USA 86: 9803-9807, 1989.

6. Zheng XM, Black D, Chambon P and Egly JM: Sequencing and expression of complementary DNA for the general transcription factor BTF3. Nature 344: 556-559, 1990.

7. Cavallini B, Huet J, Plassat JL, Sentenac A, Egly JM and Chambon P: A yeast activity can substitute for the HeLa cell TATA box factor. Nature 334: 77-80, 1988.

8. Kanno M, Chalut C and Egly JM: Genomic structure of the putative BTF3 transcription factor. Gene 117: 219-228, 1992.

9. Parvin JD, Shykind BM, Meyers RE, Kim J and Sharp PA: Multiple sets of basal factors initiate transcription by RNA polymerase II. J Biol Chem 269: 18414-18421, 1994.

10. Deng JM and Behringer RR: An insertional mutation in the BTF3 transcription factor gene leads to an early postimplantation lethality in mice. Transgenic Res 4: 264-269, 1995.

11. Bloss TA, Witze ES and Rothman JH: Suppression of CED-3-independent apoptosis by mitochondrial betaNAC in Caenorhabditis elegans. Nature 424: 1066-1071, 2003.

12. Thiede B, Dimmler C, Siejak F and Rudel T: Predominant identification of RNA-binding proteins in Fas-induced apoptosis by proteome analysis. J Biol Chem 276: 26044-26050, 2001.
13. Brockstedt E, Otto A, Rickers A, Bommert K and Wittmann-Liebold B: Preparative high-resolution two-dimensional electrophoresis enables the identification of RNA polymerase $\mathrm{B}$ transcription factor 3 as an apoptosis-associated protein in the human BL60-2 Burkitt lymphoma cell line. J Protein Chem 18: 225-231, 1999.

14. Li R, Liu XL, Du QF, Zhang S, Luo RC and Zhou SY: Proteome analysis of apoptotic K562 cells induced by harringtonine. Zhonghua Xue Ye Xue Za Zhi 25: 323-327, 2004 (In Chinese).

15. Odreman F, Vindigni M, Gonzales ML, Niccolini B, Candiano G, Zanotti B, Skrap M, Pizzolitto S, Stanta G and Vindigni A: Proteomic studies on low- and high-grade human brain astrocytomas. J Proteome Res 4: 698-708, 2005.

16. Roy L, Laboissiere S, Abdou E, Thibault G, Hamel N, Taheri M, Boismenu D, Lanoix J, Kearney RE and Paiement J: Proteomic analysis of the transitional endoplasmic reticulum in hepatocellular carcinoma: An organelle perspective on cancer. Biochim Biophys Acta 1804: 1869-1881, 2010.

17. Kusumawidjaja G, Kayed H, Giese N, Bauer A, Erkan M, Giese T, Hoheise JD, Friess $\mathrm{H}$ and Kleeff J: Basic transcription factor 3 (BTF3) regulates transcription of tumor-associated genes in pancreatic cancer cells. Cancer Biolo Ther 6: 367-376, 2007.

18. Pasquale EB: Eph receptors and ephrins in cancer: Bidirectional signalling and beyond. Nat Rev Cancer 10: 165-180, 2010.

19. Surawska H, Ma PC and Salgia R: The role of ephrins and Eph receptors in cancer. Cytokine Growth Factor Rev 15: 419-433, 2004.

20. Liu LX, Liu ZH, Jiang HC, Qu X, Zhang WH, Wu LF, Zhu AL, Wang XQ and Wu M: Profiling of differentially expressed genes in human gastric carcinoma by cDNA expression array. World J Gastroenterol 8: 580-585, 2002.

21. Green CD, Thompson PD, Johnston PG and El-Tanani MK: Interaction between transcription factor, basal transcription factor 3, and the NH2-terminal domain of human estrogen receptor alpha. Mol Cancer Res 5: 1191-1200, 2007.

22. el-Tanani MK and Green CD: Transcription factor, BTF3, and the AF-1 function of the estrogen receptor. Biochem Soc Trans 26: S252, 1998.

23. Livak KJ and Schmittgen TD: Analysis of relative gene expression data using real-time quantitative PCR and the 2(-Delta Delta C(T)) method. Methods 25: 402-408, 2001.

24. Hsu HH, Kuo WW, Ju DT, Yeh YL, Tu CC, Tsai YL, Shen CY, Chang SH, Chung LC and Huang CY: Estradiol agonists inhibit human LoVo colorectal-cancer cell proliferation and migration through p53. World J Gastroenterol 20: 16665-16673, 2014.

25. Zhang J, Zhu ZG, Ji J, Yuan F, Yu YY, Liu BY and Lin YZ: Transcription factor Spl expression in gastric cancer and its relationship to long-term prognosis. World J Gastroenterol 11: 2213-2217, 2005.

26. Wang CJ, Franbergh-Karlson H, Wang DW, Arbman G, Zhang H and Sun XF: Clinicopathological significance of BTF3 expression in colorectal cancer. Tumour Biol 34: 2141-2146, 2013.

27. Meikrantz W and Schlegel R: Suppression of apoptosis by dominant negative mutants of cyclin-dependent protein kinases. J Biol Chem 271: 10205-10209, 1996

28. Gil-Gomez G, Berns A and Brady HJ: A link between cell cycle and cell death: Bax and Bcl-2 modulate Cdk2 activation during thymocyte apoptosis. EMBO J 17: 7209-7218, 1998.

29. Leach SD, Scatena CD, Keefer CJ, Goodman HA, Song SY, Yang L and Pietenpol JA: Negative regulation of Weel expression and $\mathrm{Cdc} 2$ phosphorylation during p53-mediated growth arrest and apoptosis. Cancer Res 58: 3231-3236, 1998.

30. Hara K, Ueda S, Ohno Y, Tanaka T, Yagi H, Okazaki S, Kawahara R, Masayuki T, Enomoto T, Hashimoto Y, et al: NIH3T3 cells overexpressing CD98 heavy chain resist early G1 arrest and apoptosis induced by serum starvation. Cancer Sci 103: 1460-1466, 2012.

31. Liu Q, Zhou JP, Li B, Huang ZC, Dong HY, Li GY, Zhou K and Nie SL: Basic transcription factor 3 is involved in gastric cancer development and progression. World J Gastroenterol 19: 4495-4503, 2013.

32. Symes AJ, Eilertsen M, Millar M, Nariculam J, Freeman A, Notara M, Feneley MR, Patel HR, Masters JR and Ahmed A: Quantitative analysis of BTF3, HINT1, NDRG1 and ODC1 protein over-expression in human prostate cancer tissue. PLoS One 8: e84295, 2013.

This work is licensed under a Creative Commons Attribution-NonCommercial-NoDerivatives 4.0 International (CC BY-NC-ND 4.0) License. 